\title{
Waste landform cover system and geometrical design - integration with waste placement and landform optimisation approach
}

\author{
A Kemp O'Kane Consultants, Australia \\ I Taylor O'Kane Consultants, Australia \\ M O'Kane O'Kane Consultants, Canada
}

\begin{abstract}
One of the foremost challenges in mine landform design is the design of stable waste landforms that provide geochemical and geotechnical stability that resist long-term erosion and degradation of cover systems. Surface instability can expose reactive waste and lead to acid and metalliferous drainage, increased sedimentation of downstream waters, cause poor revegetation or related environmental impacts.
\end{abstract}

The landform surfaces are the interface between the mine landform and the surrounding environment and therefore affect long-term environmental impact. This paper focuses on practical design guidance from early concept development through to the quantitative assessments required for detailed design. This extends to discussion on overall geometry of landforms, veneer stability, cover system design and the selection of cover system materials. These factors should be considered together and integrated with internal waste landform design to provide confidence in design, and improve closure outcomes.

Surface water is intrinsically linked with surface (in)stability and the landform features, such as cover system selection, plateau grading, selection of embankment profiles and drainage structures, require an integrated approach to ensure that the design meets the stability objectives. Landform cover systems are commonly adopted for closure to manage water and oxygen ingress. In many instances the cover system forms a critical component of the closure solution to limit/mitigate the impacts of acid metalliferous drainage, and to enable rehabilitation success. Cover systems are most effective when developed in unison with the landform construction and geometry to improve the stability of the cover system, to accommodate surface water management features, and to realise efficiency in materials scheduling.

Embankment stability is affected by geometry, including slope lengths, gradients and catchments. Longer, shallower slopes have larger catchments and potentially more runoff, whilst shorter steeper slopes have less catchment but (owing to the steep grade) require less energy to mobilise waste. A balance needs to be reached for best performance which is unique for the specific material types and hydrological setting.

\section{Introduction}

Most mines across the world face long-term environmental issues leading to costly contamination treatment/s due to the inherent mineralised nature of the waste produced at mine sites. Often there is a high degree of stored acidity and potential for metal leaching from mine wastes. There is a very high expectation of managing chemically reactive mine waste typically associated with sulphide oxidation and the release of acid metalliferous and or saline drainage (Barritt \& Scott 2015); collectively referred to as acid and metalliferous drainage (AMD). Significant emphasis is placed on AMD management in mine waste management and mine closure plans. This includes managing potentially acid forming (PAF) materials and the construction of suitable cover systems. Cover systems have, in the past, been designed and retrofitted at the end of the life of the waste rock and tailings facilities. The expectation is often that the cover system would save the day when waste characteristics have changed during the life of the mine. Often waste 
placement did not consider the geochemistry and geotechnical characteristics of the waste and the mining schedule and cost benefit analysis did not allow for placing waste at stringent specifications, usually seen to be too time consuming and at a higher cost (at the time). Cover system designers often do not take into account the geometrical design of the waste landform; specifically the outer embankments where the greatest risk of erosion failure exists.

Poor waste rock dump (WRD) design and construction often lead to AMD release to groundwater and surface water. Poor cover system and geometric design often lead to AMD and sediment release to surface water and eventually exposure of PAF waste to the atmosphere. Additionally, poor cover system and outer embankment construction often exasperate the generation of AMD and release of sediment to the environment. More emphasis should be placed on quality control during waste landform internal and external construction.

An integrated cover system design including geometrical design must be combined with waste characterisation and placement design to manage reactive waste by utilising non-reactive waste and other suitable site materials to minimise the reliance on the cover system, minimise the potential for AMD generation and release, and to create a geotechnical and erosionally stable waste landform.

Landforms and cover systems must be designed using site-specific climate, materials (cover system and internal waste) and topography to be able to understand water movement at the specific site and on the specific waste landform (O'Kane \& Baisley 2014). A conceptual model/plan should be developed and understood at first to inform the design. The designer should manipulate the design components to achieve the desired performance; care must be taken that modelling programs are used and interpreted correctly. Use models to inform the engineering design; one size does not fit all.

Mine planners and stakeholders should be able to plan waste landform closure much better using a conceptual model for long-term and upfront planning followed by detailed design that considers important design concepts. This paper focusses on cover system and landform geometry design that should be integrated with waste geochemistry and load predictions that is described in Pearce et al. (2016), and waste placement risk reduction in Pearce et al. (2015).

\section{Integrated waste landform design approach}

The performance of a landform will be influenced by climate, hydrogeology, materials (geology and geochemistry), and topography/geometry. The best way to understand the overall landform is to develop a conceptual model of the current conditions and or known parameters. The model can be communicated in words or visually. Issues can be identified and strategies developed to address them. As more information is obtained or conditions change, the model should be updated to reflect the most up-to-date conceptual understanding.

The International Network for Acid Prevention (INAP) commissioned the compilation of a Global Cover System Design Technical Guidance Document that provides a "filter framework philosophy used to rapidly refine cover system alternatives through a set of site-specific filters, to more efficiently determine cover systems for further evaluation" (O'Kane \& Baisley 2014). This approach and guidance document informs the integrated design of waste landforms. The cover system design approach developed for the guidance document is very briefly described in Section 3.

Design of an integrated waste landform should be based on an understanding of the site groundwater, landform foundation conditions, base and liner requirements, waste geochemistry, internal waste placement method, gas management, cover system design and geometric design, including erosion assessments and surface water management. The site-specific design should focus on the performance objectives of the waste storage facility and be based on the design intent. Identifying challenges and opportunities relating to site location, waste schedules and material properties early can lead to long-term cost savings and reduced potential environmental impact. Different integrated alternatives should be assessed, including conducting facility specific risk assessment. The failure modes and effect analysis (FMEA) risk assessment methodology 
which is a top-down/expert-system approach to risk identification and quantification, and mitigation measure identification and prioritisation is a very suitable risk assessment tool that focusses in much more on individual components of a system than a standard environmental risk assessment.

A risk often missed is when uncontrolled gas flows upwards and out the top areas of waste facilities when it is lighter than the surrounding air, and downward and out the toe when it is heavier than the surrounding air. Geochemical reactions can deplete oxygen from air and cause unsafe conditions in the vicinity of waste facilities. Waste placement, cover system and liner design must consider the risks associated with gas flow and oxygen depletion.

Meteoritic waters percolate through a cover system and report to the underlying waste that may contain stored acidy and metals through which it seeps to the base of the waste facility. If the expected seepage is AMD it should be collected and treated before entering the natural environment through groundwater or surface water. By using quantitative stored acidy, oxygen ingress and net percolation (NP) calculations the long-term AMD potential for waste facilities can be calculated and appropriate integrated designs developed for base construction, internal waste placement and cover systems to minimise the long-term AMD potential and therefore liability.

Cover system and therefore outer embankment slopes will most likely be constructed from borrow materials and or non-acid forming (NAF) waste. In many instances the location, characteristics and volume of materials are not known or well defined leading to unacceptable risk. These parameters have to be determined before final detailed design and construction can commence.

Integrated concepts have to be further developed to detail design based on sufficient site-specific details and to be assessed for long-term performance (Kemp et al. 2014a). The assessment has to take into consideration heights and gradients of the waste facility, volumes of waste movement and cover system materials required, surface water volumes and flows, timing of implementation and quality assurance and control. Detailed engineering drawings with construction specifications and supporting design documentation should be developed for implementation and approval by regulators.

The detailed design documentation must include construction methods of placement and compaction of materials. The classification and specification of construction materials has to be included to achieve the design. In situ material testing and applicable standards should also be included in the design documentation while testing is regularly performed during construction and reported.

\section{Cover system selection and design assessment}

Most cover systems are unsaturated systems that are exposed to the atmosphere, and that limit water and gas flux into reactive mine waste. Cover systems must be geotechnically and erosionally stable to provide an overall stable landform.

The performance of a cover system and its capability to limit AMD is dependent on the climate conditions, hydrogeology, materials and vegetation, and therefore the design should be based on site-specific parameters. Cover systems are designed to manage net percolation and oxygen/gas on the plateaus and slopes of waste facilities. Net percolation and gas transport varies between the plateau, upper and lower slopes of the facility, and these variances should be considered when modelling and designing a cover system.

Net percolation into waste is controlled by diverting percolating meteoritic water by a sufficiently low permeable layer to express as surface runoff or infiltration away from reactive waste or through a store-and-release system where infiltrating water is stored within the rooting zone and is then released via evapotranspiration. All cover system types inherently contains these attributes under certain conditions; the percentage function just varies based on the conditions. The methods are described in more detail in O'Kane and Baisley (2014) and the range/continuum for managing NP is indicated in Figure 1. 


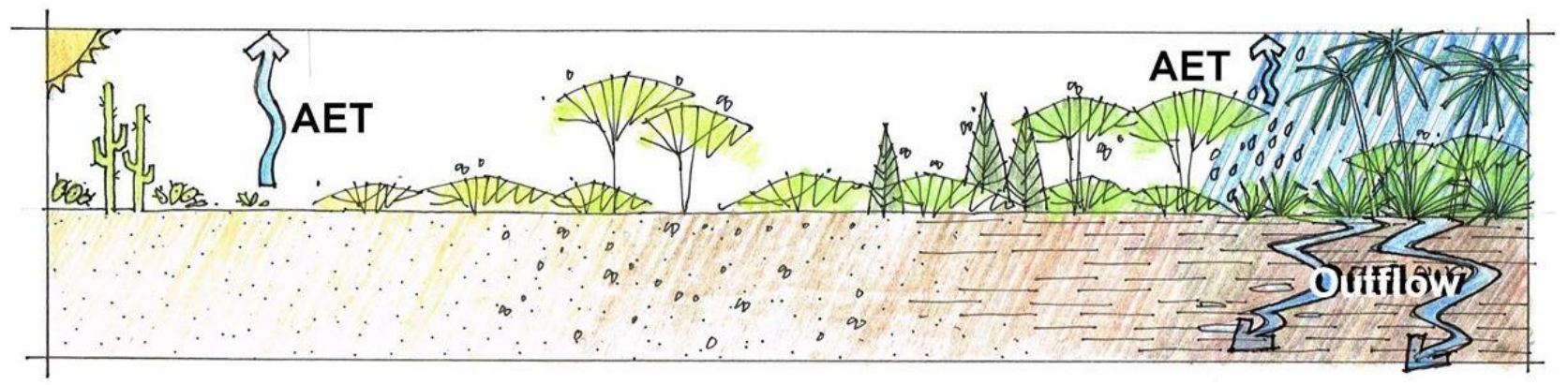

Figure 1 Cover system function continuum for managing NP with dominant water balance components identified based on climate. Arid sites from left, to temperate centre, and tropical far right of the continuum (O'Kane \& Baisley 2014)

Gas flux, and therefore AMD, can also be controlled by an engineered cover system that limits the oxidation of reactive waste. Diffusion and advective gas fluxes has to be managed by the cover system. Diffusion can be managed through the selection of finer textured cover system materials or by increasing the water content in the cover system materials to reduce the air filled porosity. A potential issue is maintaining the near saturated conditions throughout the year in varying seasonal climates. Engineering design is required to balance plant water requirements and maintaining cover system saturation. Diffusion flux can also be controlled by altering the path length or concentration differences. Managing gas flux is described in more detail in O'Kane and Baisley (2014) and the range/continuum for managing oxygen is indicated in Figure 2.

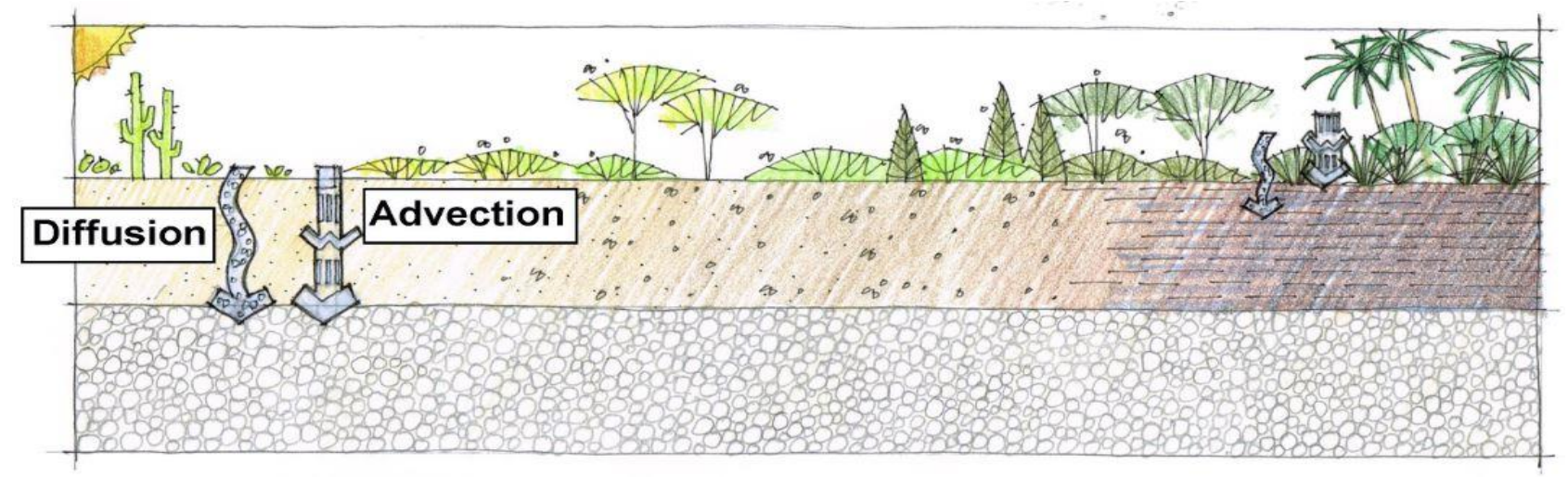

Figure 2 Cover system function continuum for managing $\mathrm{O}_{2}$ with dominant gas transport mechanisms generally identified based on climate. Arid sites from left, to temperate centre, and tropical far right of the continuum (O'Kane \& Baisley 2014)

Erosion on cover systems are generally effected by material texture, slope length, slope angle and vegetation cover. All of these aspects should be considered simultaneously when assessing the potential for erosion on a waste landform and management should aim to achieve consistent erosion across the entire landform (Kemp et al. 2014b; O’Kane \& Baisley 2014).

Erosion assessments and integration with overall landform design are described in more detail in O'Kane and Baisley (2014) and in Section 4.

Cover systems can be divided into the following categories: erosion-protection cover systems, store-and-release cover systems, enhanced store-and-release cover systems, barrier-type cover systems, and saturated soil or rock cover systems (MEND 2012; INAP 2015).

Taking all aspects described in this section into consideration and looking at characteristics of cover system assessment and engineering design that can be manipulated, it is clear that the climate is the one that cannot be changed or manipulated. Therefore, the site climate/hydrogeological setting represents the first filter that can greatly reduce the number of potential cover systems applicable for a site (O'Kane \& Baisley 2014). The 
next filter is material, followed by other site-specific considerations like topography, surface water management etc. This filter process is illustrated in Figure 3.

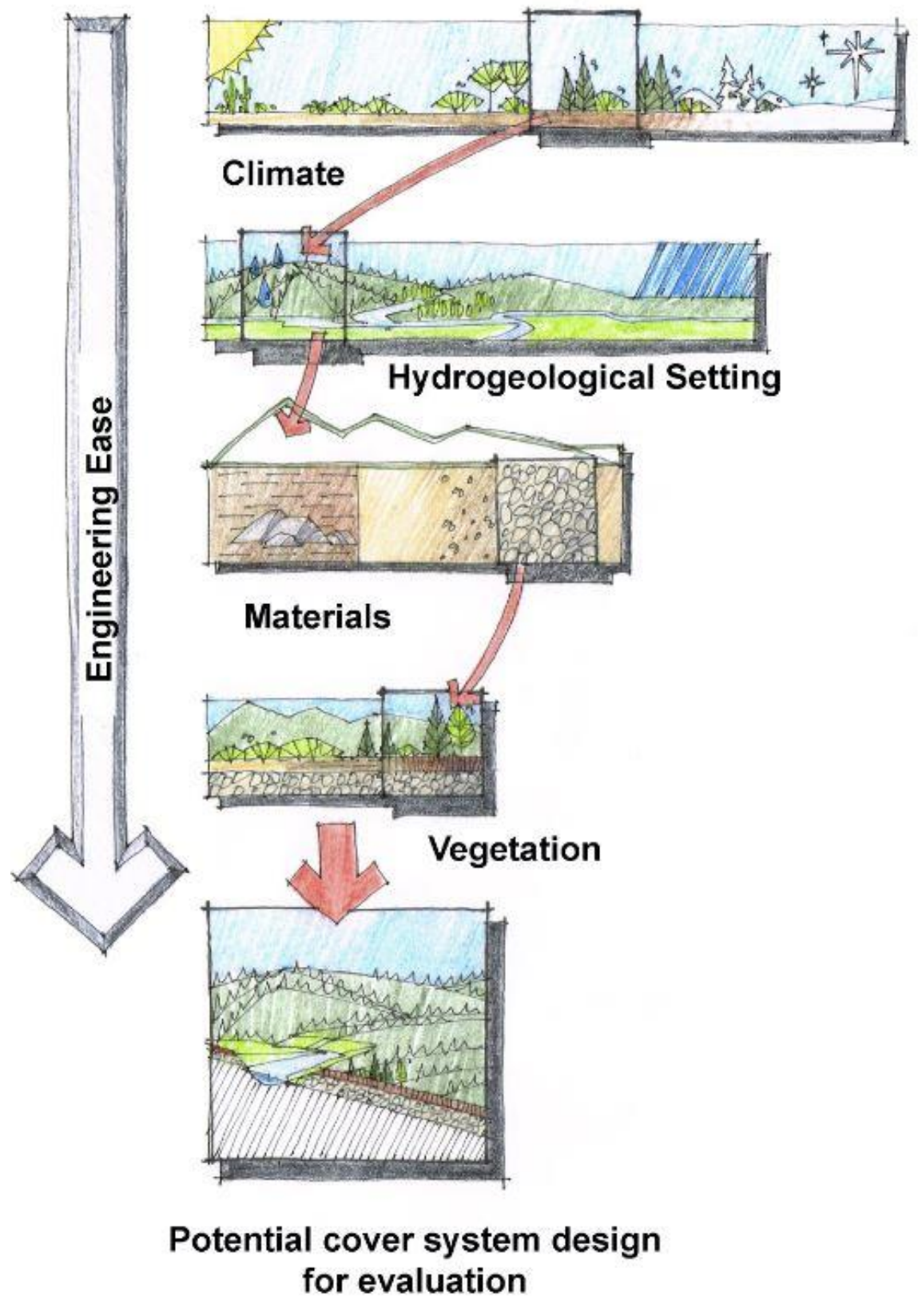

Figure 3 Filter framework for cover system design. Climate represent filter with largest impact on cover system design, while also representing a site attribute not easily modified through engineering design compared to vegetation (O'Kane \& Baisley 2014)

Cumulative impacts and knock on effects caused by failures need to be assessed. For example, dispersion of finer textured material in one area and deposition in another can lead to decreased permeability caused by hard panning leading to vegetation loss and increased runoff. Additional runoff can lead to erosion and loss of vegetation due to soil loss. Cover system modelling and assessment should take into consideration and allow sufficient depth of growth medium for vegetation establishment.

\section{$4 \quad$ Geometric design assessment}

Waste landforms are often designed and constructed with uniform and at generally acceptable geotechnically stable slopes. Slopes are often steep and include highly engineered (sized) drainage structures 
along contours with vegetation establishment following these same lines. This does not always result in erosionally stable slopes that meet closure objectives of minimum erosion, long-term sustainability and reduced long-term monitoring and maintenance liabilities. These designs are often developed without having site-specific field measured material properties. Laboratory testing and material characterisation are extremely important as input data to numerical models, engineering judgement and to understand potential environmental impact. Quantifying waste impacts (acid loads, AMD seepage rates, erosion sediment etc.) should be calculating using numerical models. The numerical model output data should be used to enhance judgement; detailed engineering assessment of the results is required to inform detailed design. Careful consideration of the dynamic nature of the materials should be included in the assessment to address the evolution of the materials and landform over time, as would happen in a natural system.

Natural slopes usually consist of a variety of shapes and sizes including concave slopes at the base. Drainage systems are not linear and vegetation develops based on hillside hydrogeology. Vegetation usually adjusts to natural changes in geometry and hydrogeology.

Failures of mine waste landforms are usually associated with gully erosion and re-establishment of surface water drainage courses (McKenna \& Dawson 1997). Additionally, linear or convex slopes will become concave, steep slopes will flatten and straight flat drainage courses will meander due to sedimentation. The sedimentation from erodible materials on slopes could lead to blockages of surface water drains leading to bench overtopping and erosion gullies down embankments.

Geotechnical stability (slumping and differential settlement) could also influence surface water flow leading to increased gully formation and material losses.

During the design, the performance objectives should be reviewed. Through the conceptual model challenges and opportunities for the specific site should be identified. Water management will include a combination of water shedding, infiltration and store-and-release that should be assessed based on climate and internal waste characteristics. Then landform aesthetics, geotechnical performance, evolution, water quality and ability to sustain vegetation should be assessed.

The plateau surface should be designed to suit cover and drainage objectives including vegetation reestablishment and habitat structure. Surface water should be kept away from the embankment; overtopping can lead to excessive gully erosion. Outer embankments should be designed based on an assessment of the material characteristics using 2D modelling tools or preferably 3D tools. Steeper slope geotechnical slip stability does not necessarily equal erosion stability, in fact it usually does not.

Figure 4 depicts a site-specific 3D model that was developed to integrate the rehabilitation of three WRDs and to design a surface water management plan. Initial assessments indicated that the material was stable for up to $30 \mathrm{~m}$ high individual dumps at the site at slopes steeper than $20^{\circ}$ but not for a $65 \mathrm{~m}$ combined height of three of the stacked dumps on site. In order to optimise material movement and containing the footprint of the reshaped dumps within allowable parameters three dumps were combined to create a single landform with a concave profile. Two-dimensional modelling could not assess or indicate the erosion potential at the top of the concave slope due to overtopping. Significant erosion potential could also not be identified by 2D modelling. However, 3D modelling indicated concentrated surface water runoff due to the concentrated concave landform shape and interface with natural topography. The 3D modelling assessment also indicated gully forming at the top of the concave slope. Engineering assessment and design lead to the requirement for armouring in the area of concentrated concave flow and crest bunding to route water away from the top of the concave slope.

Bund height should be calculated based on design rainfall depth, catchment size and cover system type. When it is required to drain plateau runoff to natural ground it should preferably be done using wide shallow swales or drainage via haul routes with shallower slopes and already traffic compacted areas. Steep drains down embankments should be avoided if possible. Also, internal drainage to relieve pore water pressure build-up that can cause veneer slip failure must be included in the design. 


\section{D assessment (terrain scale)}

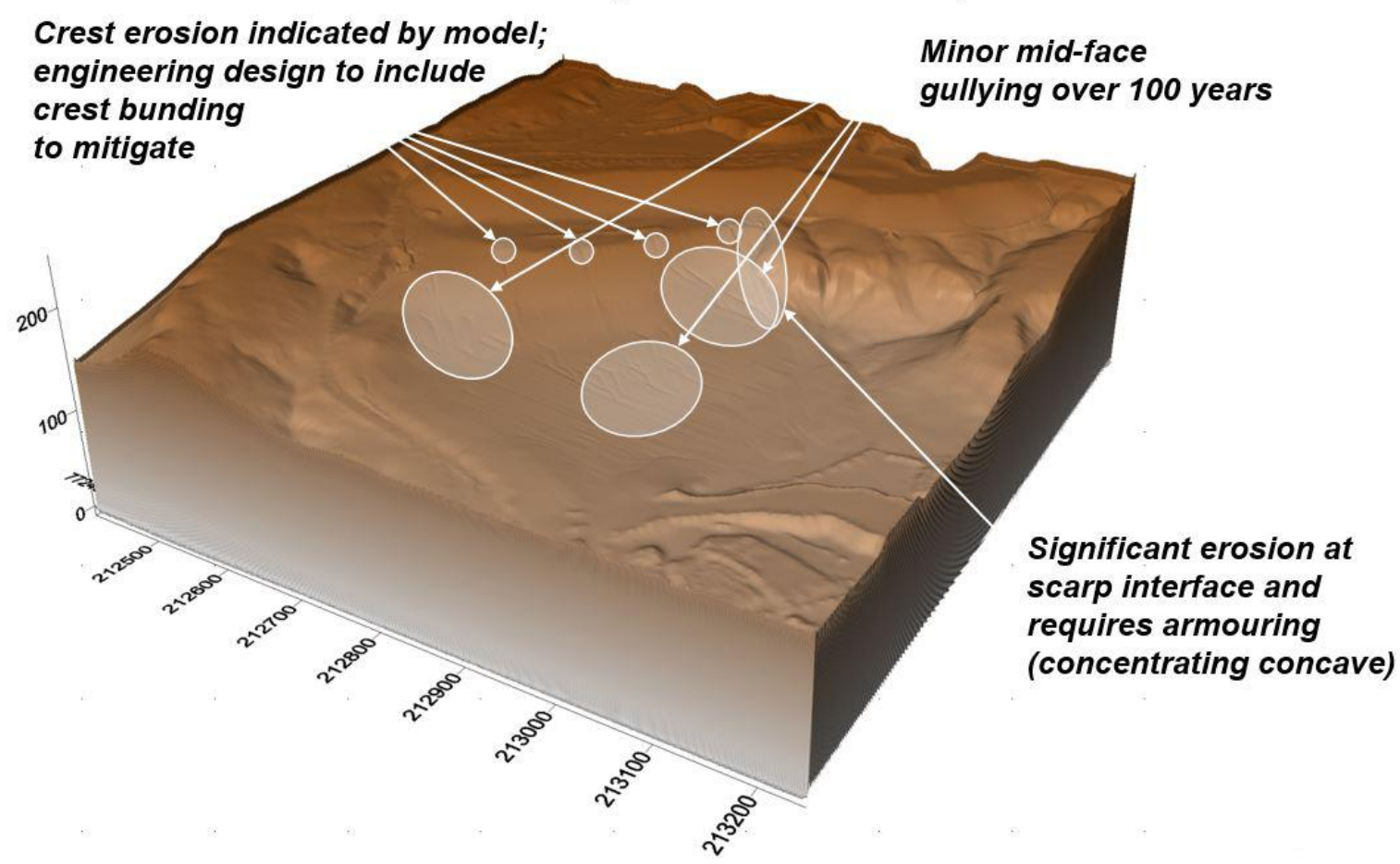

Figure 4 Utilising 3D modelling software to inform detailed design and assessment of high risk areas

Where available cover system materials are fine-grained or dispersive, armouring should be added to dissipate energy and provide erosion control. Well-graded materials have a much better chance to be stable long-term.

The design should take into consideration the characteristics of the underlying waste. If the waste is benign, the design can include promoting infiltration that will lead to net percolation into the underlying waste material.

\section{$5 \quad$ Field performance monitoring}

Currently monitoring after closure is set at three to five, maybe 10 years after closure. Due to the variability in material used for rehabilitation, the unpredictability of the climate, including climate change and time for revegetation to establish amongst other things, it is unrealistic to set a fixed timeframe for monitoring. The only thing that is for sure is how critical it is to evaluate the performance of a waste landform from a net percolation, gas flux and erosion point of view. Mine closure plans include closure objectives, and performance criteria and monitoring systems tested during operations and implemented at closure should be developed around those objectives and criteria. The monitoring period should continue until sufficient data has been collected to verify performance or show that predictive modelling results can be met.

As a minimum for every site, precipitation, air temperature, wind speed and direction, and net solar radiation should be measured.

Cover system performance monitoring and internal waste facility monitoring should be integrated and include measuring temperature, water content, pore water pressure, $\mathrm{CO}_{2}$ and oxygen. The monitoring should not only be done for compliance but more importantly for performance validation. The length of time performance monitoring is required can be shortened when predictive modelling (for cover systems and for erosion) can be validated through applying monitoring data to the model and comparing to the predictive models.

Monitoring systems should include monitoring erosion including measuring runoff volumes. The monitoring system can be used to evaluate erosion potential and can be compared to the predictive erosion model. 


\section{Conclusion}

It is very important to understand and integrate all aspects related to managing and closing mine waste facilities. There are instances where mine waste rock facilities have been constructed based on conceptual or no designs without further developing the concept or preliminary design. There are also many examples of waste rock facilities that have failed even though they were built to a design and specifications. One could argue that sometimes the designs just do not work due to material variability, extreme climatic conditions, or that the vegetation that was supposed to provide sufficient evapotranspiration and erosion stability did not establish fast enough. These waste rock facilities that do contain potentially acid forming waste also generate AMD due to exposure or cover systems not reducing net percolation or oxygen ingress sufficiently. Often the design was not based on the correct design parameters, modelling or were simply based on similar sites or generally accepted principals. Site and material specific design based on supporting modelling and assessments should be used.

This is gradually changing and the mining industry should be applauded where designs have been completed based on supporting modelling and integration of all aspects related to mine closure or where this is now part of mining and closure planning. FMEA risk assessments can be used to assess individual failure modes of integrated systems from concept stage to detailed design.

An integrated approach has to be followed from waste rock characterisation, acid load potential calculations, detailed placement design to cover system materials characterisation and modelling that inform the detailed design. Cover systems are most effective when developed in unison with the geometric design, water management design and internal waste rock facility construction. Predictive modelling using site-specific climatic and material characteristics should be used to advance concepts to detailed assessment to inform detailed design. However, the modelling has to be done correctly and interpreted to inform design.

Risks associated with each closure measure need to be understood and addressed in the detailed engineering design. High level environmental risk assessments do not always address key landform engineering risks.

During construction there has to be sufficient quality assurance and control to verify that the waste rock facility had been constructed as per the design; that is for the base, internal waste placement, external geometry and the cover system.

\section{References}

Barritt, R \& Scott, P 2015, 'Managing Waste Rock Storage Design, Can We Build a Waste Rock Dump that Works?', in A Brown, C Bucknam, J Burgess, M Carballo, D Castendyk, L Figueroa, L Kirk, V McLemore, J McPhee, M O'Kane, R Seal, J Wiertz J, D Williams, W Wilson \& C Wolkersdorfer (eds), Proceedings of 10th International Conference on Acid Rock Drainage and IMWA Conference 2015, Chile.

INAP 2015, Draft Global cover system design technical guidance document, July 2015.

Kemp, A, Taylor, I \& Hancock, G 2014a, 'Landform design for Pilbara mine site - why plan and design waste rock dumps for closure based on site-specific conditions?', in Proceedings Life-of-Mine 2014, The Australasian Institute of Mining and Metallurgy, Melbourne, pp. 47-54.

Kemp, A, Taylor, I, Pearce, SR 2014b, 'Integrated Geo-environmental Landform Assessment and Design Concepts- A Case Study' in Mine Closure 2014 Proceedings of the 9th International Conference on Mine Closure, Johannesburg.

McKenna, G \& Dawson, R 1997, 'Landscape engineering for sustainable development', Geotechnical Society of Edmonton Third Annual Symposium, Edmonton.

MEND 2012, Cold regions cover system design technical guidance document, MEND Report 1.61.5c, July 2012.

O'Kane, M \& Baisley, A 2014, 'Development of a global cover system design technical guidance document', B.C. Mine Reclamation Symposium 2014, November 2014.

Pearce, SR \& Lehane, S 2015, 'Quantitative risk assessment tools to assist with waste management and placement guidelines' in AB Fourie, M Tibbett, L Sawatsky \& D van Zyl (eds), Mine Closure 2015 Proceedings of the 10th International Conference on Mine Closure, Canada.

Pearce, JI, Weber, PA, Pearce, SP \& Scott, P 2016, 'Acid and metalliferous drainage contaminant load prediction for operational or legacy mines at closure' in Proceedings of the 11th International Conference on Mine Closure, Perth. 